\title{
Increased mortality from infectious pneumonia after occupational exposure to inorganic dust, metal fumes and chemicals
}

\author{
Kjell Torén, ${ }^{1,2}$ Ingemar Qvarfordt, ${ }^{2}$ Ingvar A Bergdahl, ${ }^{3}$ Bengt Järvholm ${ }^{3}$
}

\begin{abstract}
${ }^{1}$ Section of Occupational and Environmental Medicine, Sahlgrenska Academy, University of Gothenburg, Gothenburg, Sweden ${ }^{2}$ Section of Respiratory Medicine and Allergology, Sahlgrenska Academy, University of Gothenburg, Gothenburg, Sweden ${ }^{3}$ Occupational Medicine, Department of Clinical Medicine and Public Health, Umeå University, Umeå, Sweden
\end{abstract}

\section{Correspondence to}

Professor Dr Kjell Torén, Section of Occupational and

Environmental Medicine Sahlgrenska Academy, University of Gothenburg, Box 414, SE-405 30 Gothenburg, Sweden;

kjell.toren@amm.gu.se

Received 14 January 2011 Accepted 22 July 2011

Published Online First

19 August 2011
ABSTRACT

Objectives There are epidemiological studies indicating that exposure to metal fumes is a risk factor for infectious pneumonia. Whether occupational exposure to other agents, such as inorganic dust or chemicals, also increases the risk for infectious pneumonia is not clear. The aim of the present study was to elucidate whether occupational exposure to respiratory pollutants and irritants increases the risk for infectious pneumonia.

Design Prospective cohort study.

Setting Swedish male construction workers.

Participants 320143 male construction workers exposed to inorganic dust (asbestos, man-made mineral fibres, dust from cement, concrete and quartz), wood dust, metal fumes and chemicals (organic solvents, diisocyanates and epoxi resins) or unexposed.

Main outcome measures The cohort was followed from 1971 to 2003 and the main outcome measures were mortality to infectious pneumonia, lobar pneumonia or pneumococcal pneumonia. RRs were obtained by the person-years method and from Poisson regression models, adjusting for baseline values of age and smoking habits.

Results Among men aged 20-64 years there was increased mortality from infectious pneumonias among construction workers exposed to metal fumes (RR 2.31, $95 \% \mathrm{Cl} 1.35$ to 3.95 ), inorganic dust (RR $1.87,95 \% \mathrm{Cl}$ 1.22 to 2.87 ) and chemicals (RR $1.91,95 \% \mathrm{Cl} 1.37$ to 3.22). The mortality was also increased from both lobar pneumonia and pneumococcal pneumonia. Among men aged 65-84 years the occupational exposure to inorganic dust and chemicals was associated with slightly increased mortality from infectious pneumonia. Among groups with mutually exclusive exposures there was increased mortality from infectious pneumonias among construction workers exposed to inorganic dust, but not among those exposed to wood dust or chemicals. There were no cases among workers exposed only to metal fumes.

Conclusions Our findings indicate that exposure to inorganic dust increases the mortality from infectious pneumonias, especially lobar pneumonia and pneumococcal pneumonia. The mechanism is unclear, but the effect may be mediated through induced airways inflammation.

\section{INTRODUCTION}

A number of studies from England and Wales have shown that workers exposed to metal fumes, mainly welders, have an increased risk for infectious pneumonia. ${ }^{1-3}$ In particular, the risk has been

\section{Key messages}

What is the key question?

- Is occupational exposure to inorganic dust and fumes associated with an increased risk for infectious pneumonia?

What is the bottom line?

- The key message from the paper is that occupational exposure to inorganic dust among working age men is associated with a significantly increased risk of infectious pneumonia.

\section{Why read on?}

- The results indicate that infectious pneumonia among working age men may be regarded as occupational lung disease.

linked to lobar pneumonia as an occupational mortality study from the 1980s in England and Wales showed a doubled mortality risk from lobar pneumonia among welders. ${ }^{1}$ However, mortality was also increased among people in other occupations with possible exposure to metal fumes, such as different kinds of foundry workers. ${ }^{1}$ These observations were further explored in a casecontrol study from the West Midlands comprising hospital-admitted patients with infectious pneumonia and controls. ${ }^{2}$ The study found that questionnaire-reported exposure to metal fumes the week before admission was associated with increased risk of pneumonia (OR 1.6, 95\% CI 1.0 to 2.4$){ }^{2}$ For lobar pneumonia the risk was slightly higher. In a recent publication, Palmer and colleagues extended the analysis of occupational mortality among men to the period 1979-1990. They observed increased mortality from lobar pneumonia in occupations with probable exposure to metal fumes, such as welders, molders, core makers and sheet metal workers. ${ }^{3}$ The intriguing results from these studies have initiated a discussion on whether exposure to iron may cause oxidative damage to the lung epithelium, or alternatively, that iron is a virulence factor for certain microorganisms, especially pneumococci. ${ }^{4}$

In addition to these studies, there are several case-control studies investigating clinical and socio-economic predictors for community-acquired pneumonia, that is, infectious pneumonia Tobacco smoking and alcohol consumption are consistently shown to be risk factors for infectious pneumonia. ${ }^{5-9}$ In two of these studies, dusty 
occupations or occupational exposure to gas, fumes or chemicals were associated with increased risk for infectious pneumonia. ${ }^{7} 9$

Therefore, the risk for infectious pneumonia seems to be increased among welders and people in similar occupations exposed to metal fumes, but there are also signals in the literature that unspecific occupational exposure to dust and chemicals may increase the risk for pneumonia. To further elucidate whether occupational exposure to respiratory pollutants and irritants increases the risk for infectious pneumonia, especially lobar pneumonia, we have investigated mortality from infectious pneumonia among Swedish male construction workers exposed to metal fumes, inorganic dust, chemicals and wood dust in a prospective cohort study.

\section{METHODS}

The Swedish Construction Industry's Organisation for Working Environment, Occupational Health and Safety ('Bygghälsan') was established in 1968 to coordinate all activities concerning occupational health among Swedish construction workers. Construction workers were invited to have medical examinations at intervals of $2-5$ years. Although voluntary, it is estimated that at least $80 \%$ of eligible workers had at least one medical examination. Data from the examinations, including occupation, smoking habits, blood pressure, height and weight were registered in a central database established in the early 1970s, as previously described. ${ }^{10}{ }^{11}$ The database includes records of medical examinations performed during the period 1971-1993.

Through the personal identity number and a linkage with the National Cause of Death Register it was possible to identify subjects who had died (underlying cause) from infectious pneumonia and two subgroups: lobar pneumonia and pneumococcal pneumonia. Diagnoses from three versions of the International Classification of Diseases (ICD), ICD-8, ICD-9 and ICD-10, were used by the National Cause of Death Register between 1971 and 2003. Infectious pneumonia was defined as categories 471, 481-483, 485-486 (ICD-8 and ICD-9) and J10-J16 and J18 (ICD-10); lobar pneumonia was defined as 481 (ICD-8 and ICD-9) and J18.9 (ICD-10); pneumococcal pneumonia was defined as 481 (ICD-8 and ICD-9) and J13 (ICD-10). The classifications of pneumococcal and lobar pneumonia were overlapping for ICD-8 and ICD-9. Pneumonia caused by viruses or fungi (ICD-8 and 9484 and ICD-10 J17) was not included.

Each worker was followed from the first health examination (earliest entry 1 January 1971) until 31 December 2003. Loss to follow-up was low $(0.15 \%)$ and these workers were excluded from the analysis. The cohort of primary identified subjects was 389132 . However, the analysis was restricted to men because there were two few women (19418 in the total cohort) for a feasible analysis. Those examined at baseline before the age of 15 or after the age of 67 years were also excluded $(n=350)$. The age of retirement varied between 65 and 67 years during the period of follow-up, and few men were employed before the age of 15 years. White-collar workers (11553), foremen (30 995) and replacement occupations (6693) were excluded, resulting in a final study population of 320143 male construction workers, of whom 79305 were unexposed (referents). In our previous study there were 71778 unexposed referents based on exclusion of subjects for whom data were missing on height, weight or blood pressure. ${ }^{11}$

Smoking habit was categorised according to information from the first health examination. If information on smoking was lacking from the first examination, we used information from a later visit. In a small proportion of subjects smoking habit was unknown. These subjects were treated as a separate group in the analysis. Based on smoking habit at baseline, subjects were classified as 'never-smokers', 'ex-smokers', 'current smokers' or 'persons with unknown smoking habits'.

The occupational title at the time of the first health examination was used. Most workers remained in the same occupation throughout the study period. Among the workers who had repeated examinations, $74 \%$ reported the same occupation. A job-exposure matrix (JEM) was developed for selected exposures, as previously described. ${ }^{12}$ The JEM was based on exposure estimates from the 1970s, when each occupation was studied at visits to approximately five different sites in different geographical regions of Sweden. The estimates were made by industrial hygienists. Exposures to asbestos, asphalt fumes, cement dust, concrete dust, diesel exhaust, epoxy resins, isocyanates, man-made mineral fibres, metal fumes, organic solvents, quartz dust and wood dust were assessed, with focus on exposure during the mid 1970s. Each factor was initially graded on a categorical $0-5$ scale, but finally divided into two groups, 'exposed' or 'not exposed', with occupations that were 'not exposed' graded as zero. The occupations graded as zero on all studied exposures were considered as referents.

For the purpose of this study, the specific exposures were further merged into five broader exposure categories: exposure to inorganic dust (asbestos, cement dust, concrete dust, man-made mineral fibres or quartz), chemicals (organic solvents, epoxy resins or diisocyanates), metal fumes, wood dust and referents. Note that, in this study, workers exposed to asphalt fumes or diesel exhaust were not included in the fume-exposed group. As shown in table 1, there is an overlap among the four major exposure groups. In particular, workers classified as exposed to metal fumes or chemicals were also exposed to inorganic dust.

Common work tasks (occupations) among the subjects exposed to inorganic dust were fireproof bricklaying, drilling in stone and concrete, grinding work, stone crushing or chimney work. Common occupations among the subjects exposed to chemicals were painters, floor layers and maintenance workers. Common occupations among the referents were certain carpenters, roofers, reinforcement workers and crane operators.

\section{Statistics}

The influence of the different exposures assessed as RR was analysed by Poisson regression models adjusted for smoking and age. $^{13}$ There were separate models for the two age groups: 20-64 years and 65-84 years. Person-years were calculated from the calendar year after the first health examination, until death, emigration, or to 31 December 2003 whichever came first. The person-year analyses were stratified into 5-year age groups and into four groups according to smoking habit. ${ }^{14}$ Separate analyses were also performed among never smokers and current smokers. 95\% CIs were calculated using a Poisson distribution.

\section{RESULTS}

The distribution of men included in the analysis is shown in table 2 . There are overlapping exposures as shown in table 1 . Of

Table 1 Data on the overlap to other exposure groups

\begin{tabular}{lllll}
\hline $\begin{array}{l}\text { Major } \\
\text { exposure } \\
\text { group }\end{array}$ & $\begin{array}{l}\text { Inorganic } \\
\text { dust (\%) }\end{array}$ & Chemicals (\%) & $\begin{array}{l}\text { Metal } \\
\text { fumes (\%) }\end{array}$ & $\begin{array}{l}\text { Wood } \\
\text { dust (\%) }\end{array}$ \\
\hline Inorganic dust & 100 & 25.2 & 17.8 & 0.9 \\
Chemicals & 74.5 & 100 & 6.5 & 10.2 \\
Metal fumes & 90.8 & 11.2 & 100 & 0 \\
Wood dust & 6.2 & 24.5 & 0 & 100 \\
\hline
\end{tabular}


Table 2 Description of male construction workers included in the analysis according to exposure category

\begin{tabular}{|c|c|c|c|c|c|c|c|}
\hline Exposure & Subjects $(\mathbf{n})^{*}$ & Person- years $(\mathbf{n}) \dagger$ & $\mathbf{S}(\%)$ & XS (\%) & NS (\%) & US (\%) & Year of birth $\ddagger$ \\
\hline Referents & 79305 & 1707520 & 35.9 & 13.0 & 45.4 & 5.7 & $1949 \pm 16$ \\
\hline Inorganic dust & 155194 & 3414878 & 41.4 & 14.7 & 37.5 & 6.5 & $1944 \pm 17$ \\
\hline Chemicals & 52434 & 1092693 & 38.6 & 13.2 & 42.7 & 5.4 & $1947 \pm 18$ \\
\hline Wood dust & 21479 & 450493 & 35.0 & 13.4 & 45.8 & 5.7 & $1946 \pm 18$ \\
\hline Any exposure & 183194 & 4015838 & 40.8 & 14.5 & 38.3 & 6.4 & $1944 \pm 17$ \\
\hline
\end{tabular}

*The exposed groups are to some extent overlapping.

†Age groups $20-84$ years.

$\ddagger$ Mean \pm SD.

NS, never smokers; S, current smokers; US, persons with unknown smoking habits; XS, ex-smokers.

those exposed to metal fumes, $90.8 \%$ were also exposed to inorganic dust, and of those exposed to chemicals, $74.5 \%$ were also exposed to inorganic dust.

In total there were 773 deaths from infectious pneumonia, of which 628 occurred in the age group $>64$ years. However, of the 61 cases of pneumococcal pneumonia, 49 occurred in the age group 20-64 years.

Any occupational exposure was associated with a higher RR from infectious pneumonia among men under 65 years of age compared with men aged 65-84 years (tables 3 and 4). Among men aged 20-64 years there was increased mortality from infectious pneumonia among construction workers exposed to metal fumes (RR 2.31, 95\% CI 1.35 to 3.95), inorganic dust (RR $1.87,95 \%$ CI 1.22 to 2.87 ) and chemicals (RR 1.91, 95\% CI 1.37 to 3.22 ). Despite the limited number of cases, mortality was significantly increased from both lobar pneumonia and pneumococcal pneumonia (table 3 ). There were only three unexposed referents aged 20-64 years with pneumococcal pneumonia, therefore the precision in these estimates is low.

Among men aged 65-84 years the RR was lower and significantly increased only for infectious pneumonia after exposure to inorganic dust and chemicals (table 4). No analyses were performed for lobar pneumonia and pneumococcal pneumonia in the age group 65-84 years because of lack of cases among the referents.

There was considerable overlap among the different exposures, especially among those exposed to metal fumes or chemicals, who were also exposed to inorganic dust (table 1). When analysing the mortality in mutually exclusive exposure groups, the number of cases diminished (table 5). Exposure to inorganic dust increased the mortality from infectious pneumonia, but there was no increased mortality among those exposed to chemicals or wood dust. Among construction workers exposed only to metal fumes there were no cases of infectious pneumonia.

Smoking was a risk factor for mortality from infectious pneumonia. The mortality among current smokers was increased in the age groups 20-64 years (RR 2.77, 95\% CI 1.84 to 4.16 ) and $65-84$ years (RR $1.45,95 \%$ CI 1.22 to 1.72 ). The mortality among ex-smokers was marginally increased without statistical significance. With that in mind, we also performed occupational analyses among the never-smokers. Even if we limited the analysis to infectious pneumonia, we ran out of power. However, the risk estimates seemed to be fairly similar compared with the smoking-adjusted full models.

\section{DISCUSSION}

The results of the present study indicate that exposure to inorganic dust increases mortality from infectious pneumonia, with the highest risk for pneumococcal and lobar pneumonia. These findings give us new insights into the aetiology of community-acquired pneumonia ${ }^{15}$ because the increased mortality seems to be mainly associated with exposure to inorganic dust.

The main strength of the present study is that it is a prospective longitudinal study of a large cohort. Furthermore, we were able to use an internal control group, which is important because the healthy worker selection bias seems to be considerable. Because both the exposed workers and those in the control group were construction workers, the differences relating to socio-economic and lifestyle factors among groups can be assumed to be small. Therefore, we excluded white-collar

Table 3 Mortality risk for infectious pneumonia among male Swedish construction workers aged 20-64 years exposed to inorganic dust, chemicals, metal fumes and wood dust, adjusted for age and smoking based on Poisson regression models

\begin{tabular}{|c|c|c|c|}
\hline \multirow[b]{2}{*}{ Predictor (exposure) } & \multicolumn{3}{|l|}{$\operatorname{RR}(95 \% \mathrm{CI})$} \\
\hline & $\begin{array}{l}\text { Infectious pneumonia } \\
(n=145)\end{array}$ & $\begin{array}{l}\text { Lobar pneumonia } \\
(\mathrm{n}=49)\end{array}$ & $\begin{array}{l}\text { Pneumococcal pneumonia } \\
(\mathrm{n}=36)\end{array}$ \\
\hline \multirow[t]{2}{*}{ Referents } & 1 & 1 & 1 \\
\hline & $\mathrm{n}=26$ & $\mathrm{n}=5$ & $\mathrm{n}=3$ \\
\hline \multirow[t]{2}{*}{ Inorganic dust ${ }^{*}$} & 1.87 (1.22 to 2.87$)$ & 3.37 (1.32 to 8.57$)$ & $4.29(1.28$ to 13.86$)$ \\
\hline & $\mathrm{n}=108$ & $\mathrm{n}=37$ & $\mathrm{n}=28$ \\
\hline \multirow[t]{2}{*}{ Chemicals* } & 1.91 (1.37 to 3.22$)$ & 4.53 (1.63 to 12.58$)$ & 5.80 (1.62 to 20.88$)$ \\
\hline & $\mathrm{n}=31$ & $\mathrm{n}=14$ & $\mathrm{n}=10$ \\
\hline \multirow[t]{2}{*}{ Metal fumes* } & 2.31 (1.35 to 3.95$)$ & $3.67(1.33$ to 10.11$)$ & 5.77 (1.53 to 21.73$)$ \\
\hline & $\mathrm{n}=27$ & $\mathrm{n}=9$ & $\mathrm{n}=8$ \\
\hline \multirow[t]{2}{*}{ Wood dust* } & $0.90(0.37$ to 2.19$)$ & $1.59(0.31$ to 8.17$)$ & $2.61(0.44$ to 15.83$)$ \\
\hline & $\mathrm{n}=6$ & $\mathrm{n}=2$ & $\mathrm{n}=2$ \\
\hline \multirow[t]{2}{*}{ Any exposure ${ }^{*}$} & 1.80 (1.18 to 2.75$)$ & 3.45 (1.37 to 8.70$)$ & $4.21(1.29$ to 13.72$)$ \\
\hline & $\mathrm{n}=119$ & $\mathrm{n}=44$ & $\mathrm{n}=33$ \\
\hline
\end{tabular}

*Binary outcome $(1=\mathrm{yes}, 0=\mathrm{no})$. 
Table 4 Mortality risk for infectious pneumonia among male Swedish construction workers aged $65-84$ years exposed to inorganic dust, chemicals, metal fumes and wood dust, adjusted for age and smoking based on Poisson regression models

\begin{tabular}{ll}
\hline & $\begin{array}{l}\text { Infectious } \\
\text { pneumonia } \\
(\mathbf{N}=\mathbf{6 2 8}) \\
\mathbf{R R}(\mathbf{9 5} \% \mathbf{C l})\end{array}$ \\
\hline Predictor (exposure) & 1 \\
\hline Referents & $\mathrm{n}=99$ \\
& $1.36(1.09$ to 1.68$)$ \\
Inorganic dust* & $\mathrm{n}=468$ \\
& $1.40(1.08$ to 1.81$)$ \\
Chemicals* & $\mathrm{n}=141$ \\
& $1.16(0.82$ to 1.62$)$ \\
Metal fumes* & $\mathrm{n}=51$ \\
& $1.30(0.94$ to 1.78$)$ \\
Wood dust* & $\mathrm{n}=61$ \\
Any exposure* & $1.31(1.06$ to 1.63$)$ \\
& $\mathrm{n}=529$ \\
\hline
\end{tabular}

*Binary outcome $(1=$ yes, $0=$ no $)$.

workers, foremen and replacement occupations, similar to a previous paper. ${ }^{11}$

Although the outcome-pneumonia as the underlying cause of death-may include a few misclassified cases in the oldest age groups, the diagnoses on the death certificates in the younger age group, 20-64 years, are likely to be accurate.

The exposure classification was based on a JEM, and the matrix was based on workers' first occupation, but we have data showing that most construction workers remain in the same occupation throughout their working life, such as carpenters, welders and plumbers. ${ }^{12}$ The JEM was based on exposure estimations from the 1970s. It originated from an extensive exposure assessment project employing several industrial hygienists with experience in the construction industry. However, it is likely that the workers in the control group had some occupational exposure, albeit lower than in the exposed group, for several reasons: there is general dust exposure at most construction sites, so no one in the cohort is really unexposed; our exposure assessment only takes the occupational title given at the first health examination into account; and referents may have had an exposed occupation before or after the first examination. This may cause underestimations of the risks. There was considerable overlap among the different exposures. This was especially obvious for exposure to metal fumes and chemicals. When analysing mutually exclusive exposure groups, we found that most subjects exposed to metal fumes were also exposed to inorganic dust.

The classification of smoking habits in the study was not time dependent and did not differentiate between smokers with high and low daily tobacco consumption. Different exposure groups may have had different cumulative exposure to tobacco smoke, that is, different pack-years. This potential confounding, however, should not have had a significant influence on the results because separate analyses of never-smokers only, showed similar results.

Two interesting studies in this field ${ }^{16} 17$ and a subsequent scientific discussion ${ }^{18} 19$ have recently been published. In a study from Korea the incidence of hospitalisation because of infectious pneumonia was found to be increased among workers exposed to cement, lime, plaster and plaster products. ${ }^{16}$ The comparison group was noise-only exposed workers, and the age span was 20-69 years. Among men $(n=47)$ the standardised admission rate was 1.54 (95\% CI 1.13 to 2.05) and among women ( $\mathrm{n}=8)$, it was 3.23 (95\% CI 1.40 to 6.37). There was also an increased standardised admission rate of 1.64 (95\% CI 1.25 to 2.11$)(n=59)$ among male foundry workers. These findings support an association between exposure to inorganic dust and the risk for hospitalisation due to infectious pneumonia. The study included all types of pneumonia, including those caused by viruses and fungi. There was no separate analysis for lobar pneumonias and the study lacked adjustment for smoking habits. The association was also observed among foundry workers, but the authors pointed out that foundry workers are exposed to both inorganic dust and metal fumes.

A Canadian study analysed the risk of hospitalisation due to community-acquired pneumonia among patients older than 65 years. ${ }^{17}$ Controls were randomly selected from the general population. Pneumonia was defined as radiologically confirmed pneumonia among patients admitted to hospitals. The patients were interviewed when admitted and controls were interviewed by telephone. Self-reported regular exposure to gases, fumes or chemicals at work was associated with a hospitalisation rate due to pneumonia of 5.78 ( $95 \%$ CI 4.22 to 7.91 ). This finding was not commented on in the paper, ${ }^{17}$ but was highlighted in a letter and in a subsequent reply to the editor. ${ }^{18} 19$ The correspondence pointed out that this study indicates that occupational exposure to gas, dust and fumes was associated with an increased risk for pneumonia that seemed to be long lasting. This was not in line with previous studies in which the risk seems to be highest

Table 5 Mortality risk for infectious pneumonia among male Swedish construction workers aged 20-84 years

\begin{tabular}{|c|c|c|c|}
\hline \multirow[b]{3}{*}{ Predictor (exposure) } & \multicolumn{3}{|c|}{ Infectious pneumonia } \\
\hline & \multicolumn{3}{|l|}{ RR $(95 \%$ Cl) } \\
\hline & All & $20-64$ years & $65-84$ years \\
\hline \multirow[t]{2}{*}{ Referents } & 1 & 1 & 1 \\
\hline & $\mathrm{n}=125$ & $\mathrm{n}=26$ & $\mathrm{n}=99$ \\
\hline \multirow[t]{2}{*}{ Inorganic dust* } & $1.42(1.16$ to 1.75$)$ & 1.65 (1.03 to 2.63$)$ & 1.36 (1.08 to 1.71$)$ \\
\hline & $\mathrm{N}=350$ & $\mathrm{n}=56$ & $\mathrm{n}=294$ \\
\hline \multirow[t]{2}{*}{ Chemicals* } & $1.07(0.50$ to 2.29$)$ & NA & NA \\
\hline & $\mathrm{n}=7$ & & \\
\hline Metal fumes* & NA & NA & NA \\
\hline \multirow[t]{2}{*}{ Wood dust* } & $1.27(0.92$ to 1.76$)$ & $1.18(0.45$ to 3.06$)$ & 1.25 (0.88 to 1.77$)$ \\
\hline & $\mathrm{n}=51$ & $\mathrm{n}=5$ & $\mathrm{n}=46$ \\
\hline
\end{tabular}

The risks are shown among groups with non-overlapping exposures to inorganic dust, chemicals, and wood dust, adjusted for age and smoking based on Poisson regression models. There were no cases among the metal-fume-exposed workers.

*Binary outcome $(1=$ yes, $0=$ no). NA, Not analysed. 
among occupationally active men. ${ }^{2}$ However, our analysis indicates to some extent a long-lasting effect, as we also observed significantly increased risks among subjects aged 65-84 years.

The main finding in the present study is that different kinds of occupational exposures present at a construction site, such as inorganic dust, metal fumes and chemicals, increased the mortality from infectious pneumonia. The risk seemed to be further increased if the outcome was restricted to lobar or pneumococcal pneumonia. The most common exposure was inorganic dust, and the subjects exposed to either metal fumes or chemicals were also exposed to inorganic dust. When analysing non-overlapping exposures we found that exposure to mineral dust was associated with increased mortality, but it was not possible to assess the risk among only metal-fume-exposed workers.

As discussed in other studies, most workers (not only construction workers) exposed to metal fumes are also exposed to inorganic dust. In our study the workers with combined exposure to inorganic dust and metal fumes seemed to have higher mortality compared with those only exposed to inorganic dust. However, we lack the power to assess whether there is an interaction between these two exposures.

One possible mechanism is that inorganic dust and metal fumes induce inflammation and oxidative stress in the airways, ${ }^{20}$ both of which may increase susceptibility to pathogenic microorganisms, such as pneumococci. Mice exposed to dust from hurricane Katrina developed increased airway resistance, increased inflow of neutrophils and lymphocytes, and decreased levels of macrophages in the airways. ${ }^{21}$ The Katrina dust consisted of inorganic dust, silica, semi-volatile chemicals and a variety of toxic metals. Similar kinds of dust are probably present at most construction sites. A Swedish investigation from 2004 showed that the threshold limits for silica dust and total dust were exceeded in $65 \%$ of measurements on construction sites during renovation. ${ }^{22}$ Therefore, the findings from the present study may also reflect a risk that still exists for construction workers.

The RR was higher in the younger (20-64 years) age group, indicating the importance of current (ongoing) exposure. This is in line with the findings from a previously cited case-control study in which the risk estimates peaked when occupational exposure to metal fumes occurred in the weeks before the onset of pneumonia. ${ }^{2}$

There is a strong co-morbidity among infectious pneumonia and coronary heart disease, chronic obstructive pulmonary disease, diabetes and chronic liver disease. ${ }^{8}$ There is also a strong association between tobacco smoking and alcohol consumption and the risk for infectious pneumonia and pneumococcal pneumonia. ${ }^{23}$ This is evident in our study because subjects who were current smokers at baseline had a higher mortality risk from infectious pneumonia and lobar pneumonia. However, we have no data on alcohol consumption and we cannot exclude that our results are biased by alcohol abuse. Heavy drinking and tobacco smoking are often linked, ${ }^{24}$ and our models are adjusted for smoking, which to some extent adjusts for such confounding.

In summary, our findings indicate that exposure to inorganic dust at construction sites increases mortality from infectious pneumonia. The mechanism is unclear but the effect may be mediated through induced airways inflammation.
Funding Funding was provided by the Swedish Council for Worklife research and Social Science (FAS) and the Swedish Heart and Lung Foundation.

Competing interests All authors have completed the Unified Competing Interest form at http://www.icmje.org/coi_disclosure.pdf lavailable on request from the corresponding author) and declare (1) no support from any company for the submitted work; (2) no relationships with any companies that might have an interest in the submitted work in the previous 3 years; (3) their spouses, partners, or children have no financial relationships that may be relevant to the submitted work; and (4) no non-financial interests that may be relevant to the submitted work.

Ethical approval The study was approved by the Committee of Ethics at Umeå University.

Contributors $\mathrm{KT}, \mathrm{IQ}$ and $\mathrm{BJ}$ designed the study, BJ managed and analysed the data, IAB was responsible for exposure assessments. All authors participated in the interpretation, drafting and critical review of the results.

Provenance and peer review Not commissioned; externally peer reviewed.

\section{REFERENCES}

1. Coggon D, Inskip $\mathrm{H}$, Winter $\mathrm{P}$, et al. Lobar pneumonia: an occupational disease in welders. Lancet 1994;344:41-4.

2. Palmer KT, Poole J, Ayres JG, et al. Exposure to metal fume and infectious pneumonia. Am J Epidemiol 2003;157:227-33.

3. Palmer KT, Cullinan P, Rice $S$, et al. Mortality from infectious pneumonia in meta workers: a comparison with deaths from asthma in occupations exposed to respiratory sensitisers. Thorax 2009;64:983-6.

4. Palmer KT, McNeilsll-Love R, Poole JR, et al. Inflammatory responses to the occupational inhalation of metal fume. Eur Respir J 2006;27:366-73.

5. Almirall J, Bolibar I, Balanzo X, et al. Risk factors for community-acquired pneumonia in adults: a population-based case-control study. Eur Respir J 1999;13:349-55.

6. Almirall J, Gozález CA, Bolibar I, et al. Proportion of community-acquired pneumonia cases attributable to tobacco smoking. Chest 1999;116:375-9.

7. Farr BM, Bartlett CL, Wadsworth J, et al. Risk factors for community-acquired pneumonia diagnosed upon hospital admission. Respir Med 2000:94:954-63.

8. Almirall J, Bolibar I, Serra-Prat M, et al. New evidence of risk factors for communityacquired pneumonia: a population-based study. Eur Respir J 2008;31:1274-84.

9. Loeb M, Neupane B, Walter SD, et al. Environmental risk factors for community acquired pneumonia hospitalization in older adults. J Am Geriatr Soc 2009:57:1036-40.

10. Järvholm B, Stenberg A. Suicide mortality among electricians in the Swedish construction industry. Occup Environ Med 2002;59:199-200.

11. Torén K, Bergdahl IA, Nilsson T, et al. Occupational exposure to particulate air pollution and mortality due to ischemic heart disease and cerebrovascular disease. Occup Environ Med 2007:64:515-19.

12. Bergdahl IA, Torén K, Eriksson K, et al. Increased mortality in COPD among construction workers exposed to inorganic dust. Eur Respir J 2004;23:402-6.

13. Aitkin M, Anderson D, Francis B, et al. Statistical modelling in GLIM. Oxford: Clarendon Press, 1990.

14. Berry G. The analysis of mortality by the subject-years method. Biometrics 1983:39:173-84.

15. Mandell L. Community acquired pneumonia [editorial]. BMJ 2010;341:c2916

16. Koh DH, Moon KT, Kim JY, et al. The risk of hospitalization for infectious pneumonia in mineral dust exposed industries. Occup Environ Med 2011:68:116-19.

17. Neupane B, Jerret M, Burnett RT, et al. Long-term exposure to ambient air pollution and risk of hospitalization with community-acquired pneumonia in older adults. $\mathrm{Am} J$ Respir Crit Care Med 2010;181:47-53.

18. Hnizdo E, Storey E. Occupational exposure to gases, fumes, or chemicals and risk of community-acquired pneumonia. Am J Respir Crit Care Med 2010;182:1087-8.

19. Loeb M, Neupane B, Jerret M. From the authors. Am J Respir Crit Care Med 2010;182:1088.

20. Castranova V, Frazer DG, Manley LK, et al. Pulmonary alterations associated with inhalation of occupational and environmental irritants. Int Immunopharmacol 2002;2:163-72.

21. Wang K, You D, Balakrishna S, et al. Sediment from hurricane Katrina: potential to produce pulmonary dysfunction in mice. Int J Clin Exp Med 2008;1:130-44.

22. Norén J0. Byggdamm vid ROT-arbeten. Rapport. [In Swedish]. Stockholm, Sweden: Arbetsmiljöverket, 2005:2.

23. Klemets $\mathbf{P}$, Lyytikäinen 0 , Ruutu $P$, et al. Risk of invasive pneumococcal infections among working age adults with asthma. Thorax 2010;65:698-702.

24. Romberger DJ, Grant K. Alcohol consumption and smoking status: the role of smoking cessation. Biomed Pharmacother 2004;58:77-83. 